
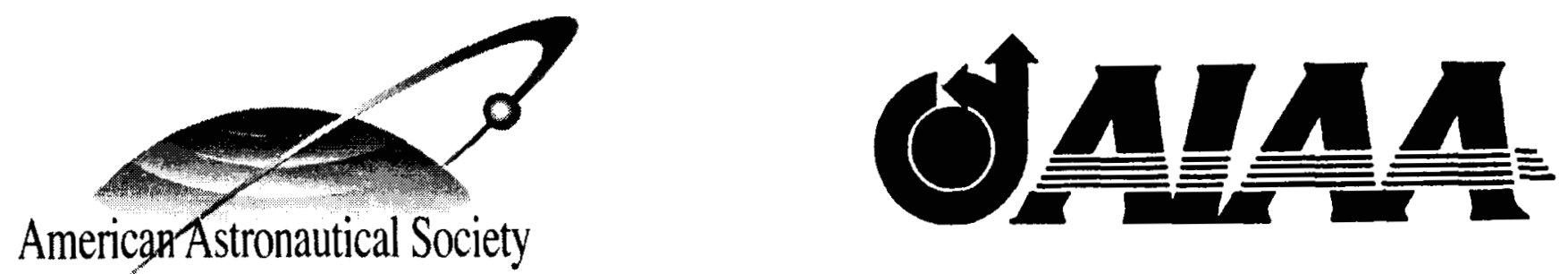

\title{
Mars Exploration Rover Six-Degree-Of-Freedom Entry Trajectory Analysis
}

Prasun N. Desai, Mark Schoenenberger and F. M. Cheatwood

NASA Langley Research Center Hampton, VA

\section{AAS/AIAA Astrodynamics Specialists Conference}

Big Sky Resort, Big Sky, Montana, August 3-7, 2003

AAS Publications Office, P.O. Box 28130, San Diego, CA 92198 
AAS 03-642

\title{
MARS EXPLORATION ROVER SIX-DEGREE-OF-FREEDOM ENTRY TRAJECTORY ANALYSIS
}

\author{
Prasun N. Desai, ${ }^{*}$ Mark Schoenenberger, ${ }^{\dagger}$ and F. M. Cheatwood ${ }^{\ddagger}$ \\ NASA Langley Research Center, Hampton, VA
}

The Mars Exploration Rover mission will be the next opportunity for surface exploration of Mars in January 2004. Two rovers will be delivered to the surface of Mars using the same entry, descent, and landing scenario that was developed and successfully implemented by Mars Pathfinder. This investigation describes the trajectory analysis that was performed for the hypersonic portion of the MER entry. In this analysis, a six-degree-of-freedom trajectory simulation of the entry is performed to determine the entry characteristics of the capsules. In addition, a Monte Carlo analysis is also performed to statistically assess the robustness of the entry design to off-nominal conditions to assure that all entry requirements are satisfied. The results show that the attitude at peak heating and parachute deployment are well within entry limits. In addition, the parachute deployment dynamics pressure and Mach number are also well within the design requirements.

\section{INTRODUCTION}

The Mars Exploration Rover (MER) mission's "Spirit" and "Opportunity" spacecrafts were successfully launched on June $10^{\text {th }}$ and July $7^{\text {th }}$ of 2003 , respectively. The Landers are headed to the equatorial region of Mars with Spirit targeted to land in Gusev crater $\left(14.59^{\circ} \mathrm{S}, 175.3^{\circ} \mathrm{E}\right)$ on January $4^{\text {th }} 2004$ and Opportunity to land in Meridiani Plains $\left(1.98^{\circ} \mathrm{S}, 5.94^{\circ} \mathrm{W}\right)$ on January $25^{\text {th }} 2004$. Each Lander will carry a rover which will explore the surface of Mars making in-situ measurements. However, unlike the Mars Pathfinder Sojourner rover, these rovers are larger and more capable accommodating an increased suite of science instruments, and will be able to traverse greater distances during surface operations. Reference 1 gives an overview of the MER mission.

Both Landers will deliver the rovers to the surface utilizing the same entry, descent, and landing (EDL) scenario that was developed and successfully implemented by Mars Pathfinder (MPF). ${ }^{2}$ The capsule will decelerate with the aid of an aeroshell, a supersonic parachute, retrorockets, and air bags for safely landing on the surface (see Fig. 1). Reference 3 gives a description of the EDL system.

\footnotetext{
* Senior Aerospace Engineer, Aerospace Systems and Concepts Competency, p.n.desai@larc.nasa.gov

† Aerospace Engineer, Aerospace Systems and Concepts Competency,m.schoenenberger@larc.nasa.gov

† Senior Aerospace Engineer, Exploration Program Office, f.m.cheatwood@larc.nasa.gov

Copyright (C) 2003 by The American Astronautical Society
} 


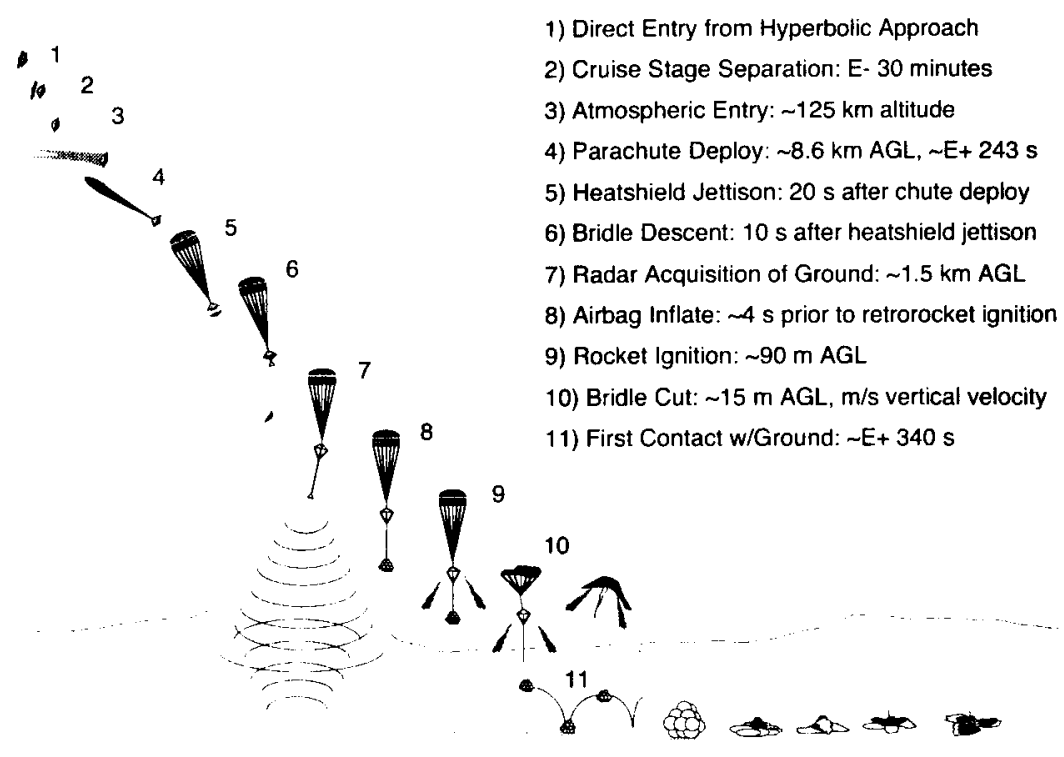

Figure 1 MER Entry, Descent, and Landing Sequence

In addition, the MER Landers utilize the same capsule configuration (a 70-deg sphere-cone) as Mars Pathfinder as shown in Figure 2. However, the entry similarities between Mars Pathfinder and MER end there. The MER design entry mass is much higher, the entry velocity is lower, and the entry local time is different. These differences lead to a different entry profile for MER as it descends through Mars' atmosphere. Figure 3 compares the entry profile for MER, Mars Pathfinder, and Viking. As seen, the MER entry is bounded by the Viking and Mars Pathfinder profiles. Table 1 summarizes the entry characteristics of Viking, Mars Pathfinder, and MER.

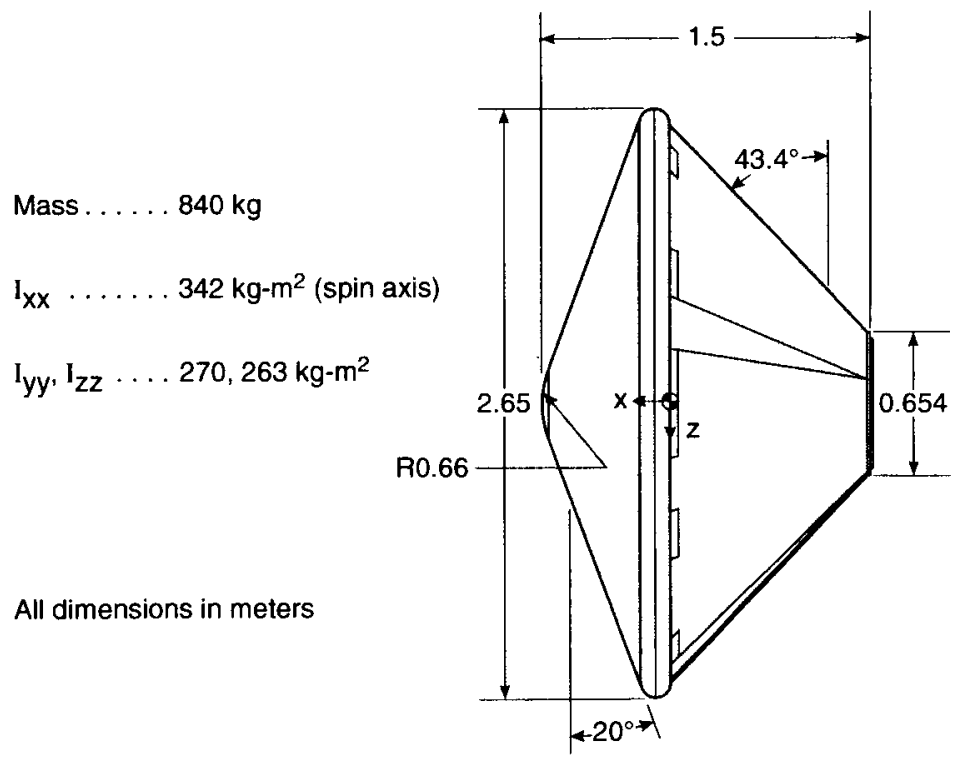

Figure 2 MER Entry Capsule Configuration 


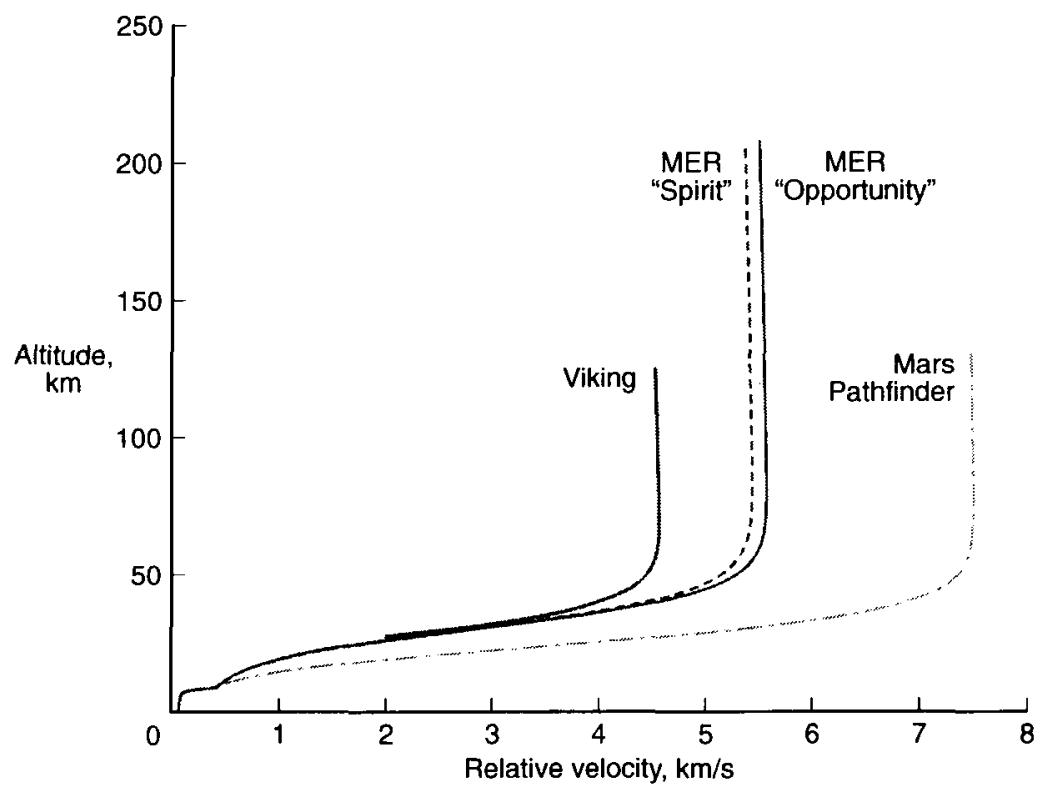

Figure 3 Entry Profile Comparison

Table 1

COMPARISON OF ENTRY CHARACTERISTICS

Forebody geometry, deg

Aftbody geometry, deg

Relative Entry Velocity, $\mathrm{km} / \mathrm{s}$

Relative Entry FPA, deg

Entry Local Time

Mass, $\mathrm{kg}$

$\mathrm{m} /\left(\mathrm{C}_{\mathrm{D}} \mathrm{A}\right), \mathrm{kg} / \mathrm{m}^{2}$

$\mathrm{x}_{\mathrm{cg}} / \mathrm{D}$

Nominal a, deg

L/D

G\&C

Viking I, II
70
$39 / 62$ (biconic)
$4.5,4.42$
-17.6
--
930
63.7
0.221
-11.1
0.18
3-axis (active)

MER

70

49

5.5

$-12$

Afternoon

840

89.8

0.27

62.3

0.27

0

0

spin stabilized
0

0

spin stabilized

Approximately 15 minutes prior to entry, the capsule will be separated from the cruise stage. The capsule has no active control system, so the $2 \mathrm{rpm}$ spin rate maintain its entry attitude during coast until atmospheric interface (nominally $0^{\circ}$ angle-of-attack). Throughout the atmospheric entry, the passive capsule will rely solely on aerodynamic stability for performing a controlled descent through all aerodynamic flight regimes: free molecular, transitional, hypersonic-continuum, and supersonic. The capsule must possess sufficient aerodynamic stability to minimize any angle-of-attack excursions during the severe heating environment. Additionally, this stability must persist through the supersonic regime to maintain a controlled attitude at parachute deployment.

This paper describes the trajectory analysis that was performed for the hypersonic portion of the MER entry. In this analysis, a six degree-of-freedom (DOF) trajectory 
simulation of the entry (from cruise-stage separation to parachute deployment) is performed to determine the entry characteristics of the MER capsules. Of specific interest is the attitude dynamics of the capsule during the descent near peak heating and at parachute deployment, along with the parachute deployment conditions (dynamics pressure and Mach number). This information is necessary for defining requirements for the thermal protection and parachute subsystems. In addition, a Monte Carlo analysis is also performed to statistically assess the robustness of the entry design to off-nominal conditions to assure that all EDL requirements are satisfied.

\section{ANALYSIS}

\section{Aerodynamics}

The aerodynamic database utilized for the MER capsule in the trajectory simulation analyses is constructed from a variety of computational and experimental sources, each chosen as the most appropriate method for the flight regime for which they are employed. The general structure of the database is a matrix of pitch damping, pitching moment, and normal and axial force coefficients defined for a range of angles-of-attack and speeds. An overlapping parabola interpolation scheme is employed to smoothly blend the aerodynamics between the data points and different flight regimes. For a given flight condition and capsule attitude, the database provides estimates of $C_{A}, C_{N}, C_{Y}, C_{m}, C_{n}, C_{m q}$ and $C_{n r}$ for use in six-DOF simulations. This approach is essentially the same as that utilized for Mars Pathfinder. ${ }^{4}$ However, the flow conditions for each data point are tailored to the MER entry trajectory, and a significant number of additional data points have been incorporated to increase the fidelity of this database. In addition, experimental work was performed to characterize the pitch damping of the MER capsule at supersonic conditions, and a large number of additional supersonic computational fluid dynamic (CFD) solutions were performed to increase confidence in the predictions of the capsule attitude at parachute deployment.

The variety of sources for the aerodynamics is required because the MER capsule traverses many different flow regimes (free molecular, transitional, hypersoniccontinuum, supersonic) during its entry. The different flight regimes are defined by the dominant flow physics of the particular portion of the entry trajectory. The regimes, starting from atmospheric interface, include: free molecular, where the particles of the atmosphere are modeled individually without interaction with each other; transitional, where collisions among atmosphere molecules are important, but the flow cannot be modeled as a continuum; hypersonic-continuum, where the flow is governed by the Navier-Stokes equations, with possible nonequilibrium gas chemistry effects, and negligible base pressure contributions to the aerodynamics; and supersonic continuum, where flow chemistry is in equilibrium and base pressure becomes an important part of the vehicle aerodynamics. A schematic of the database and these regimes is shown in Figure 4. 


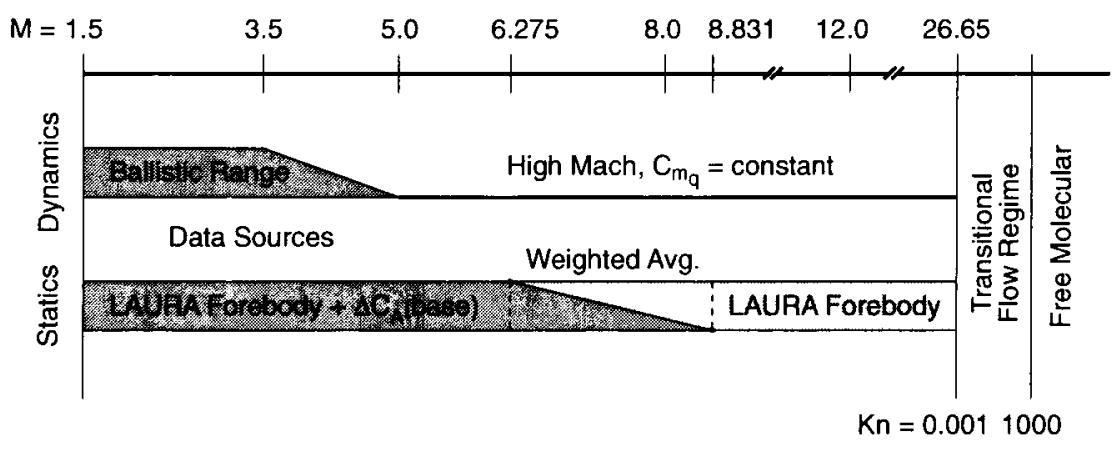

Figure 4 Schematic of MER Aerodynamic Database

The free molecular aerodynamic calculations were performed with the DACFREE code. ${ }^{5}$ In the transitional flow regime, Direct Simulation Monte Carlo (DSMC) calculations were performed using the DAC code. ${ }^{6}$ In the hypersonic- and supersonic-continuum regimes, a matrix of solutions from the computational fluid dynamics code LAURA (Langley Aerothermodynamic Upwind Relaxation Algorithm $)^{7}$ describe the aerodynamics. These sources are blended to form a comprehensive database, which describe the aerodynamics of the MER capsule for the expected flight conditions.

While LAURA solutions over the entire capsule were calculated for Mach numbers below 6, only the forebody contributions were included in the aerodynamic coefficients. In this regime, resolving the backshell pressure distribution of the flow field accurately for blunt bodies is very difficult. Therefore, a base pressure correction was applied to the axial force coefficient to account for the contribution from the capsule backshell. This correction was developed from Viking flight data ${ }^{9}$ and was used in the same fashion for Mars Pathfinder. No correction was added to the pitching moment or normal force coefficients, since the effect on these coefficients is minimal. The success of both the Viking and MPF missions validate this approach. Figure 5 shows the matrix of LAURA solutions in the MER database.

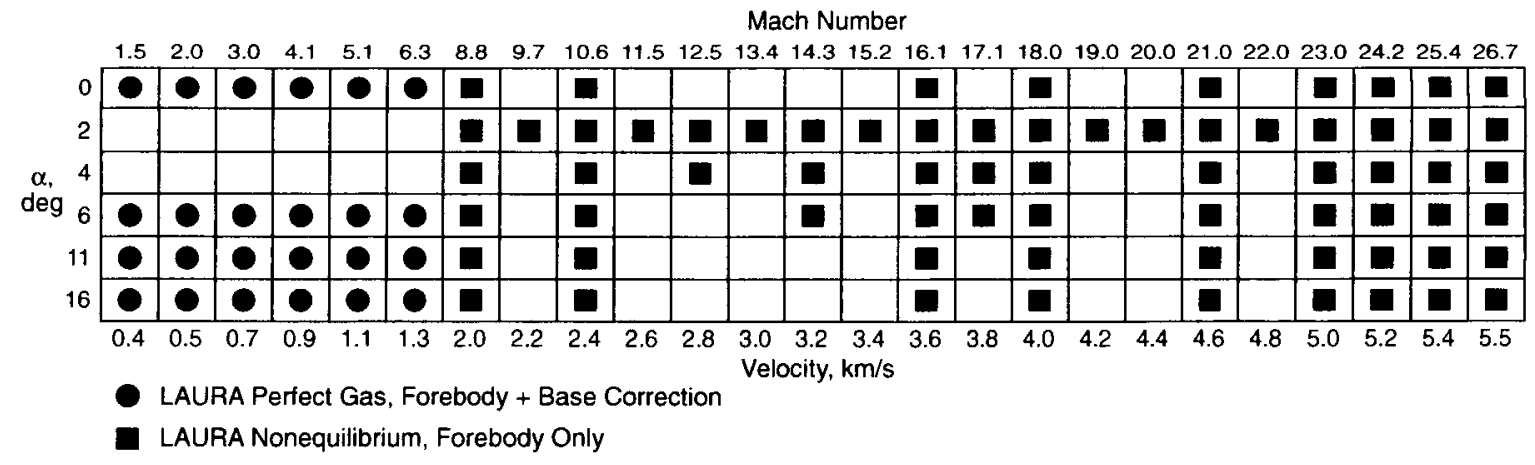

Figure 5 Matrix of LAURA CFD Solutions Used in MER Aerodynamic Database

Figure 6 shows a surface plot of the static stability parameter $\mathrm{C}_{\mathrm{m} \alpha}$ in the continuum regime. At two velocities in the hypersonic regime, the pitching moment coefficient be- 
comes positive at low angles-of-attack $\left(<2^{\circ}\right)$, indicating that the capsule is statically unstable in these regions. These instabilities are bounded, since as the angle-of-attack increases above $2^{\circ}$, the pitching moment becomes negative leading to a stable behavior. The bounded instability at $5.5 \mathrm{~km} / \mathrm{s}$ (Mach 27) is due to the gas chemistry of the forebody flow changing from non-equilibrium to equilibrium. The bounded instability at $3.6 \mathrm{~km} / \mathrm{s}$ (Mach 16) occurs because of a movement of the sonic line on the leeward side of the capsule from the shoulder to the spherical nose cap. These instabilities were predicted for Mars Pathfinder with LAURA and their existence and location was verified with flight data. ${ }^{10}$ These instabilities predicted for MER are less severe than MPF. This consequence is primarily due to the lower entry velocity that results in less energetic chemical reactions.

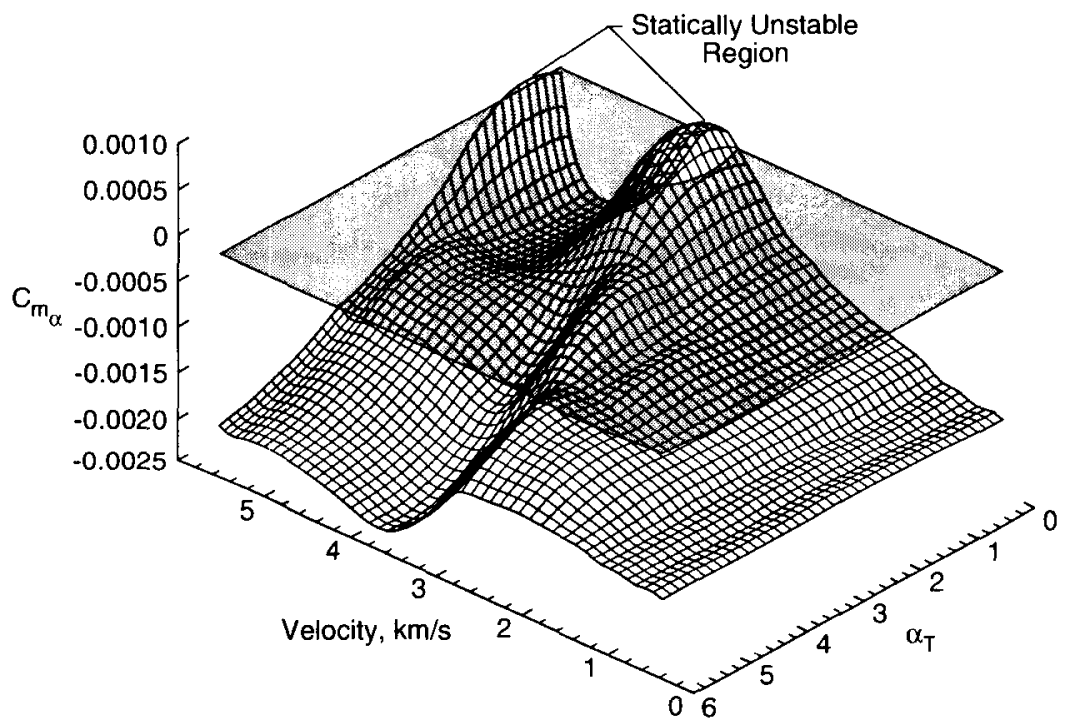

Figure 6 LAURA Hypersonic/Supersonic $C_{m \alpha}$ (per degree) Surface

The pitch damping characteristics of the MER capsule were determined experimentally through an extensive series of ballistic range tests. Presently, computational methods cannot predict damping behavior well. These tests were conducted at the Aeroballistic Research Facility at Eglin Air Force Base, where $70 \mathrm{~mm}$ diameter models were shot from a powder-charge gun at supersonic speeds down a $200 \mathrm{~m}$ range. The range is instrumented with 50 spark shadowgraph stations. Shadowgraphs taken from two orthogonal views at each station provided the model position and time as it flew past. The model trips a light beam at each station that simultaneously initiates the spark light source for the shadowgraphs and marks the time of the exposure. A total of 26 shots were performed having a range of initial attitudes and Mach numbers, along with three model center-ofgravity positions $\left(\mathrm{x}_{\mathrm{cg}} / \mathrm{D}=0.27,0.30\right.$ and 0.33 ), since the final location was not well know during the design phase. With this data of time, position, and attitude, two independent data reduction efforts were conducted to extract the pitch damping coefficient curves using parameter identification methods. ${ }^{11,12}$ The results from both efforts were in good agreement and added confidence to the results. 
Figure 7 shows the pitch damping coefficient $\mathrm{C}_{\mathrm{my}}$ versus Mach number and angle-ofattack. Note the low-speed, low-angle region where $\mathrm{C}_{\mathrm{my}}$ is positive, indicating that the MER capsule is dynamically unstable (i.e., excitation rather than damping). As a result, the capsule attitude increases while in this region. Negative $C_{m q}$ values indicate that the capsule is dynamically stable (i.e., the attitude will damp out). This behavior is in qualitative agreement with Viking forced oscillation data. ${ }^{13}$ This dynamic instability is bounded similar to the hypersonic static instabilities. As the capsule angle-of-attack increases, $\mathrm{C}_{\mathrm{mq}}$ becomes negative damping out the attitude. This behavior tends towards a limit cycle phenomenon.

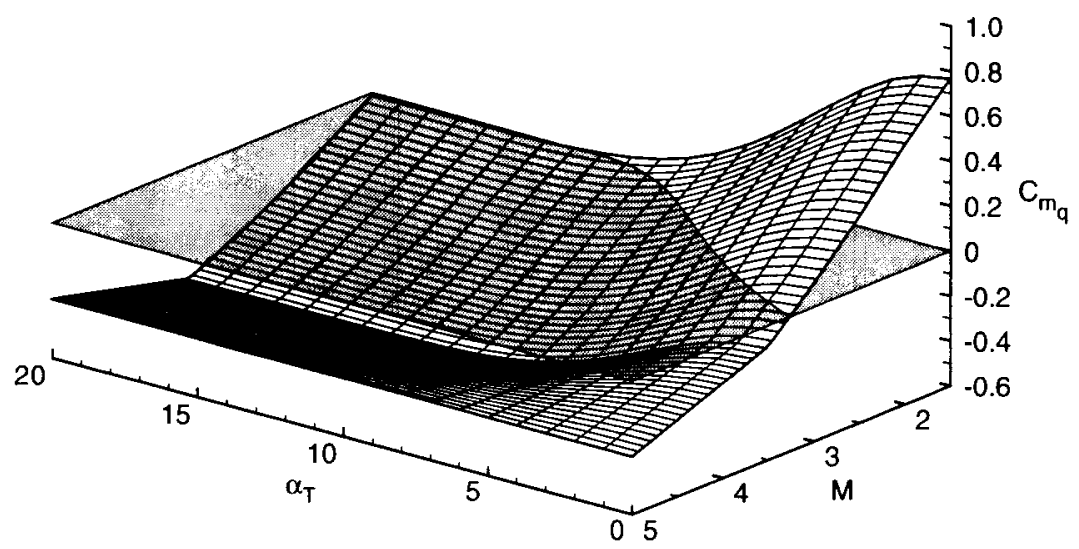

Figure 7 Supersonic Pitch Damping Surface from Ballistic Range Data

The supersonic pitch damping coefficient is a function of capsule geometry and center-of-gravity location. As a result, the Viking forced oscillation data is not appropriate for other configurations (see Table 1); although, this data was used in the Mars Pathfinder database since no ballistic range tests were performed for that mission. Consequently, the MPF capsule attitude was under-predicted in this supersonic flight region. ${ }^{2}$ This ballistic range data reveal that the MER (and Pathfinder) capsule configuration is more dynamically unstable than the Viking configuration. As a result, the MER capsule oscillations will grow to larger amplitudes than if the Viking data had been utilized.

\section{Trajectory Simulation}

The trajectory analysis is performed using the six-DOF (degree-of-freedom) versions of the Program to Optimize Simulated Trajectories (POST). ${ }^{14}$ This program has been utilized previously for similar applications. ${ }^{4,15,16}$ The trajectory simulation begins post cruise-stage separation of the MER capsule, continues through atmospheric entry, and ends at parachute deployment. The trajectory analysis incorporates atmospheric and gravitational models, cruise-stage/capsule separation attitude and attitude rates, mass properties, and the previously described aerodynamics. The validity of the present approach has been demonstrated through comparisons between the Mars Pathfinder pre-flight predictions of the flight dynamics and the actual flight data, which show a very good agreement. ${ }^{2,10}$ The KassSchofield atmosphere model utilized for the entry was specifically developed for the MER 
mission. This model takes into account the specific MER season, local time, and landing location in estimating the nominal and dispersed density and wind profiles.

During the entry, off-nominal conditions may arise which affect the descent profile. These off-nominal conditions can originate from numerous sources, such as capsule mass property measurement uncertainties, cruise-stage/capsule separation attitude and attitude rate uncertainties, and limited knowledge of the flight-day atmospheric properties (density and winds). Additionally, computational uncertainty with the aerodynamic analysis and uncertainties with the parachute deployment algorithm are contributing sources of uncertainty. The mission uncertainties that are considered in the Monte Carlo analysis are grouped into two categories (exo-atmospheric and atmospheric) and are listed in Tables 2 and 3, respectively, along with their corresponding 3-o variances. A Gaussian distribution is utilized for sampling the variation in each parameter.

\section{Table 2 \\ EXO-ATMOSPHERIC MISSION UNCERTAINTIES}

\begin{tabular}{|c|c|}
\hline Mass Properties & 3-o Variance \\
\hline $\mathrm{cg}$ offset along axis of symmetry. &. $\pm 20 \mathrm{~mm}$ \\
\hline $\mathrm{cg}$ offset off spin axis.......................... & $\pm 2.8 \mathrm{~mm}$ \\
\hline $\begin{array}{l}\text { Moments of inertia }\left(I_{x x}, I_{y y}, I_{z z}\right) \ldots . \\
\text { Cross products of inertia }\left(I_{x y}, I_{x z},\right.\end{array}$ & $\begin{array}{l} \pm 10 \%, \pm 10 \%, \pm 10 \% \\
\pm 1.6 \mathrm{~kg}-\mathrm{m}^{2}, \pm 2.0 \mathrm{~kg}-\mathrm{m}^{2}, \pm 1.6 \mathrm{~kg}-\mathrm{m}^{2}\end{array}$ \\
\hline Post-Separation State & \\
\hline State Vector (flight-path angle var & $\pm 0.13 \mathrm{deg}$ \\
\hline Pitch and yaw attitude.................. & $\pm 1.7 \mathrm{deg}, \pm 2.69 \mathrm{deg}$ \\
\hline Pitch and yaw rates & $\pm 0.4 \mathrm{deg} / \mathrm{s}, \pm 0.4 \mathrm{deg} / \mathrm{s}$ \\
\hline Roll rate...... & $\pm 1.2 \mathrm{deg} / \mathrm{s}$ \\
\hline
\end{tabular}

Table 3

ATMOSPHERIC MISSION UNCERTAINTIES

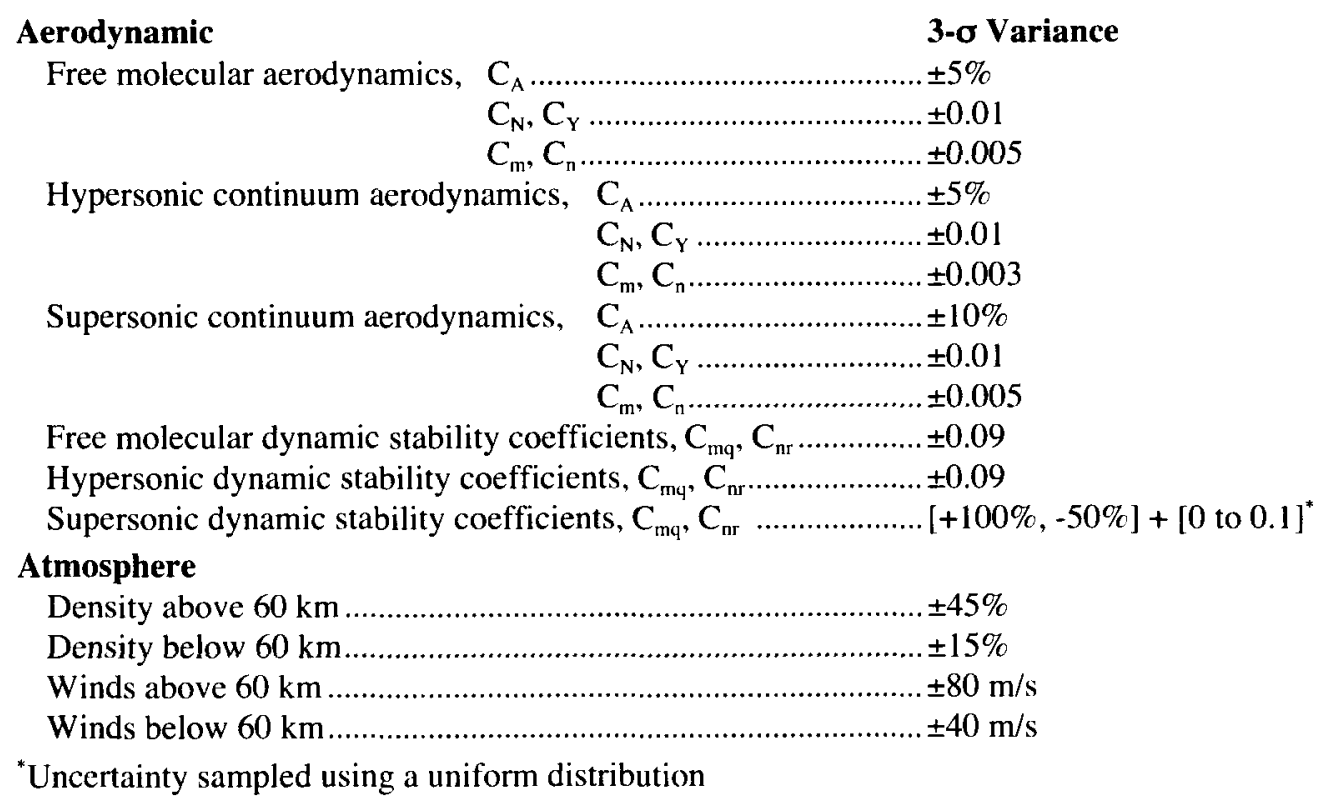




\section{RESULTS AND DISCUSSION}

\section{Nominal MER Entry}

To overcome the effects of the high $840 \mathrm{~kg}$ entry design mass, the nominal MER entry utilizes a fairly shallow planet-relative flight-path angle of $-12^{\circ}$ as compared to the Mars Pathfinder entry of $-13.8^{\circ}$. Note, the final entry masses of the two MER Landers are a little lower than this design mass value used in the analysis. This shallow entry was necessary to increase the parachute deployment altitude so that sufficient timeline was available for performing the remaining terminal EDL events (as described in Fig.1). Consequently, MER will entry with the shallowest flight-path angle of any other Mars mission to date. However, this shallow flight-path angle has the advantage of reducing the entry heating and deceleration environments as compared to Mars Pathfinder. A peak heat rate value of $50 \mathrm{~W} / \mathrm{cm}^{2}$ and deceleration of 6.4 Earth $\mathrm{g}$ is experienced by MER as compared to approximately $105 \mathrm{~W} / \mathrm{cm}^{2}$ and 20 Earth g for Mars Pathfinder, respectively.

The nominal MER attitude profile is shown in Figure 8. Note, the total angle-ofattack $\alpha_{T}$ is used to denote capsule attitude since the capsule is axisymmetric, where $\alpha_{T}$ is the included angle between the capsule axis of symmetry and the atmospheric-relative velocity vector. Also illustrated are the various aerodynamic flow regimes during the descent. The MER entry attitude is targeted to $0^{\circ}$ at atmospheric interface. Prior to atmospheric interface, the capsule is in the free molecular flow regime and exhibits a non-zero attitude as a consequence of the inertial pointing from cruise-stage separation. The attitude decreases towards zero as the atmospheric interface point approaches. As the capsule descends into the atmosphere, aerodynamic forces begin to build which cause the capsule to trim to a non-zero $\alpha_{\mathrm{T}}$.

In the transitional regime, the capsule attitude is observed to increase to $\sim 1^{\circ}$. As the capsule continues the descent into the continuum regime, the first of the two static instabilities is encountered as predicted by the aerodynamics, and an abrupt increase in $\alpha_{\mathrm{T}}$ to a little over $2^{\circ}$ is observed at $125 \mathrm{~s}$. As the capsule passes through this instability, it becomes aerodynamically stable again resulting in a decrease in the attitude down to $\sim 1^{\circ}$ near the peak heating region of the entry. At approximately $190 \mathrm{~s}$, the capsule encounters the second static instability as seen by another abrupt increase in $\alpha_{\mathrm{T}}$ to almost $3^{\circ}$. Upon continued descent, the capsule becomes statically stable again, and the attitude decreases to small values $\left(<0.5^{\circ}\right)$ until the start of the supersonic regime. A final increase in attitude is observed below Mach 3 (time of $275 \mathrm{~s}$ ) as a consequence of the capsule being dynamically unstable at low angles-of-attack as described by the aerodynamics. The attitude increases to $\sim 1^{\circ}$ at parachute deployment. 


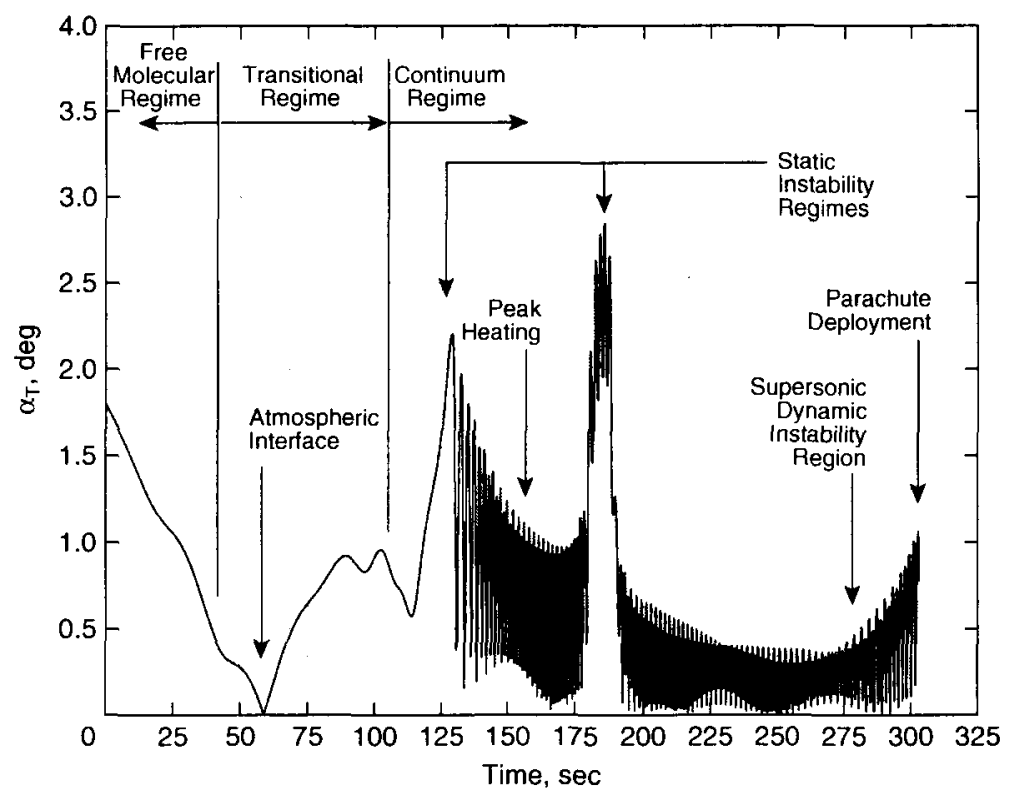

Figure 8 Nominal Capsule Entry Attitude Profile

Parachute deployment nominally occurs at $304 \mathrm{~s}$ at a target value of $725 \mathrm{~N} / \mathrm{m}^{2}$. A parachute deployment algorithm, which utilizes accelerometer measurements during the descent, initiates the deployment process. This target deployment dynamic pressure value is higher than the $600 \mathrm{~N} / \mathrm{m}^{2}$ used by Mars Pathfinder. This value has been selected to provide sufficient time for performing all the remaining terminal EDL events as shown in Fig. 1, and maybe reduced prior to landing. However, as the parachute deployment dynamic pressure is reduced, the capsule attitude will continue to grow beyond that shown in Figure 8. As a result, a lower bound exists which cannot be exceeded to avoid concerns of large attitudes at deployment that may pose problems for a successful parachute inflation.

\section{Monte Carlo Dispersion Analysis}

To statistically assess the robustness of the MER entry design, off-nominal conditions are simulated to address uncertainties that may arise during the descent. The impact of multiple uncertainties occurring simultaneously is ascertained by performing a Monte Carlo dispersion analysis. Two thousand random, off-nominal trajectories are simulated varying the parameters listed in Tables 2 and 3 between their respective upper and lower bounds.

The results from the Monte Carlo dispersion analysis are graphically presented in Figures 9-12 and tabulated in Table 4. Figures 9-11 show the distribution in the capsule attitude at atmospheric interface, peak heating, and at parachute deployment, respectively. At atmospheric interface, the statistical mean total angle-of-attack is $4.7^{\circ}$, with an observed maximum $\alpha_{\mathrm{T}}$ of $10.1^{\circ}$. This variation in $\alpha_{\mathrm{T}}$ at atmospheric interface is entirely a result of the uncertainty in the cruise-stage/capsule separation dynamics. As the capsule encounters the atmosphere, aerodynamic stability damps the attitude to small values so 
that by peak heating, the mean $\alpha_{\mathrm{T}}$ is $0.8^{\circ}$ with a maximum of $3.3^{\circ}$. As the capsule approaches parachute deployment, the dynamic aerodynamic instability increases the attitude to a mean $\alpha_{\mathrm{T}}$ of $1.1^{\circ}$ with a maximum of $4.4^{\circ}$. These attitudes are well within the design requirement of $10^{\circ}$ at atmospheric interface and peak heating, and $13^{\circ}$ at parachute deployment. The resulting conditions at parachute deployment are shown in Figure 12, where a scatter plot illustrates the deployment dynamic pressure verses Mach number for each case simulated. The deployment conditions are also well within the parachute deployment box limits which is outlined. The maximum dynamic pressure requirement of $810 \mathrm{~N} / \mathrm{m}^{2}$ is just slightly violated, while the maximum Mach number is well below the limit. The actual design upper limit on the parachute dynamic pressure is over $900 \mathrm{~N} / \mathrm{m}^{2}$. However, to maintain margin, the simulation limit has been set to $810 \mathrm{~N} / \mathrm{m}^{2}$.

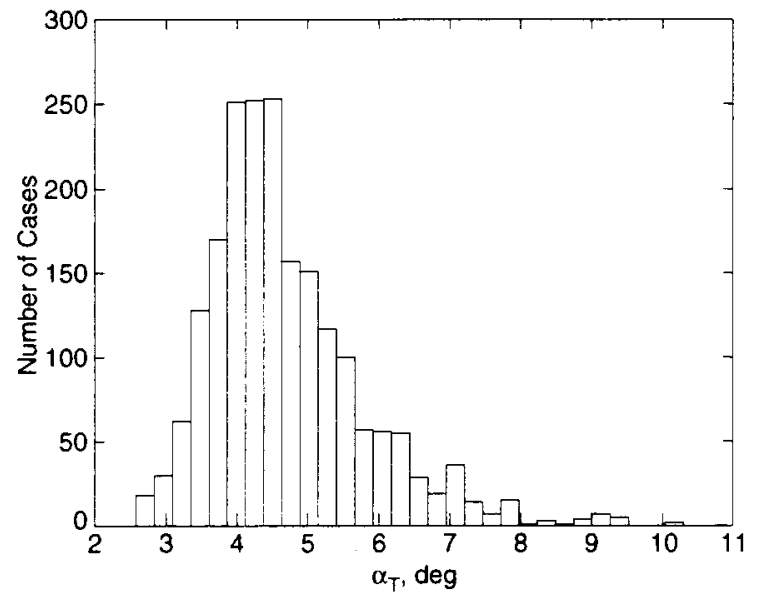

Figure 9 Distribution of Capsule Attitude at Atmospheric Interface

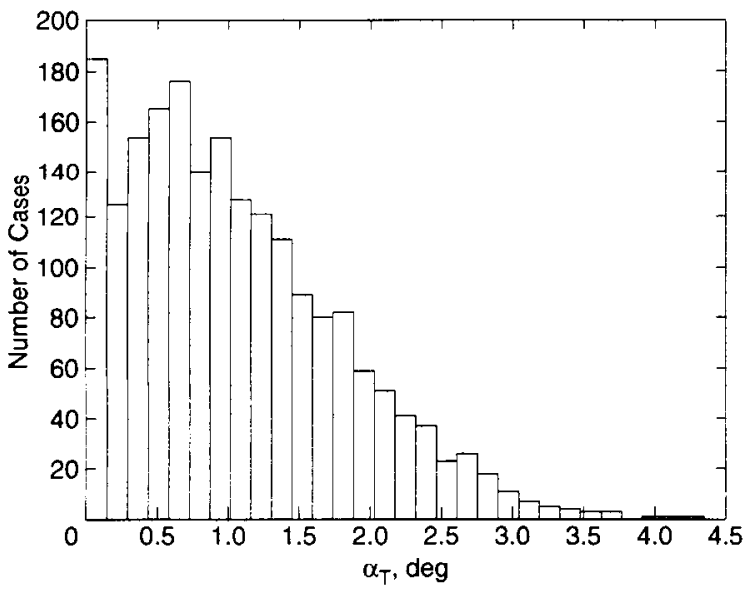

Figure 11 Distribution of Capsule Attitude at Parachute Deployment

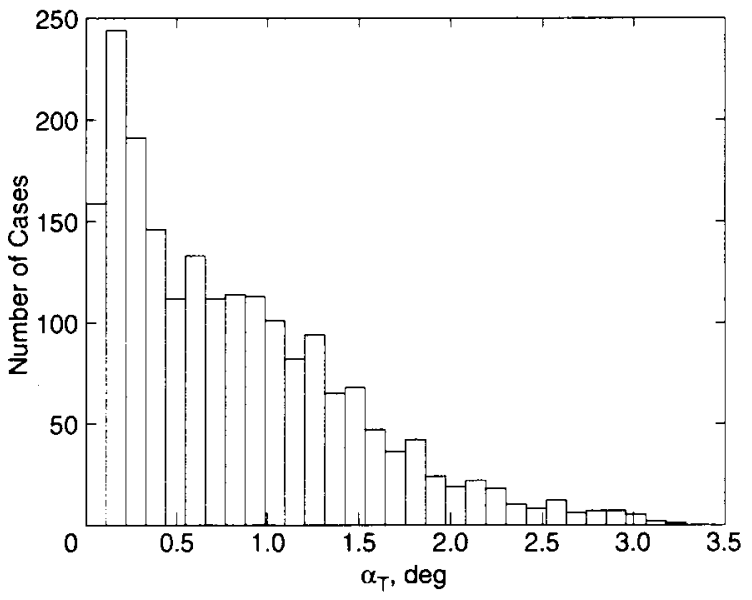

Figure 10 Distribution of Capsule Attitude at Peak Heating

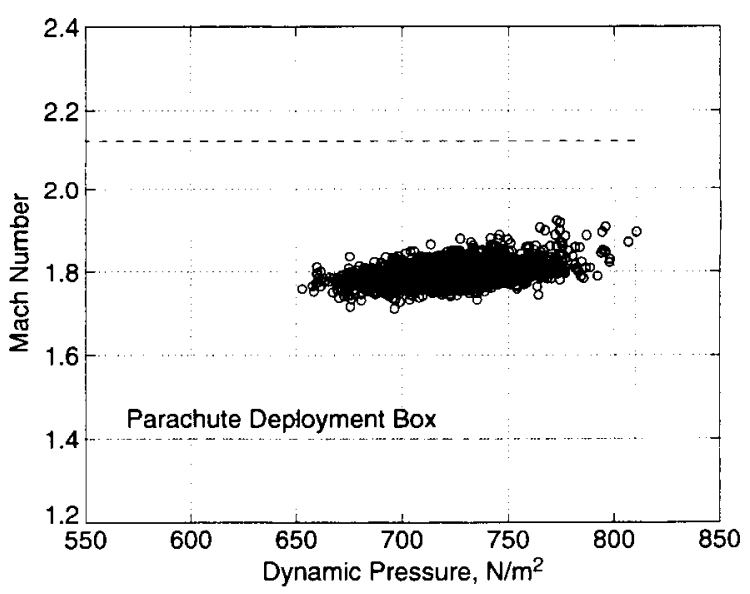

Figure 12 Variation in Parachute Deployment Conditions 


\section{Table 4}

\section{MONTE CARLO DISPERSION ANALYSIS STATISTICS}

$\begin{array}{lllll} & \text { Mean } & \text { Min } & \text { Max } & \text { 3-o } \\ \text { Attitude at Atmospheric Interface, deg } & 4.7 & 2.6 & 10.3 & 3.3 \\ \text { Attitude at Peak Heating, deg } & 0.8 & 0.0 & 3.3 & 1.9 \\ \text { Attitude at Parachute Deployment, deg } & 1.1 & 0.0 & 4.4 & 2.3 \\ \text { Deployment Dynamic Pressure, N/m }{ }^{2} & 723 & 653 & 811 & 71 \\ \text { Deployment Mach Number } & 1.79 & 1.71 & 1.92 & 0.08 \\ \text { Entry Deceleration, Earth g } & 6.4 & 5.8 & 6.9 & 0.47\end{array}$

\section{CONCLUSIONS}

The Mars Exploration Rover (MER) mission will land two rovers that will carry out scientific investigation of the surface of Mars. Both Landers will deliver the rovers to the surface utilizing the same entry, descent, and landing (EDL) scenario that was developed and successfully implemented by Mars Pathfinder. The Landers will decelerate with the aid of an aeroshell, a supersonic parachute, retrorockets, and air bags for safely landing on the surface. During the atmospheric flight, the capsules rely solely on aerodynamic stability for traversing all flight regimes to minimize any attitude excursions. To demonstrate that all entry constraints are satisfied, a six-degree-of-freedom (DOF) entry trajectory analysis is performed. Through this investigation, the capsule aerodynamics and sixDOF entry dynamics are defined.

Aerodynamic analysis of the MER entry has shown that the capsule is aerodynamically stable throughout most of the atmospheric flight. However, at two specific locations during the entry (velocity of $5.5 \mathrm{~km} / \mathrm{s}$ and $3.6 \mathrm{~km} / \mathrm{s}$ ), the capsule is found to be statically unstable at low angles-of-attack. Also, at supersonic speeds, the capsule is observed to be dynamically unstable again for low angles-of-attacks. These instabilities cause abrupt increases in the capsule attitude. However, in all of the flight regimes, the capsule is aerodynamically stable at higher angles-of-attack. Therefore, any increase in attitude resulting from these instabilities is bounded. A maximum angle-of-attack of $3^{\circ}$ is observed for the nominal MER entry.

A Monte Carlo dispersion analysis is performed to statistically assess the robustness of the MER entry design to off-nominal conditions that may arise during the descent. The results show that the attitude at peak heating and parachute deployment are well within entry limits of $10^{\circ}$ and $13^{\circ}$, respectively. A maximum attitude of $3.3^{\circ}$ at peaking heating and $4.4^{\circ}$ at parachute deployment is observed. In addition, the variation in the parachute deployment dynamic pressure and Mach number are also well within the design requirements. 


\section{ACKNOWLEDGEMENTS}

The authors would like to extend their appreciation to all the members of the MER EDL design team for their contributions. However, specifically, the authors would like to thank Chia-Yen Peng for estimating the cruise-stage/capsule separation dynamics, David Kass for development of the atmosphere model, and Ben Riggs for calculating the capsule mass properties, all of who work at the Jet Propulsion Laboratory.

\section{NOTATION}

\begin{tabular}{|c|c|}
\hline CFD & Computational Fluid Dynamics \\
\hline cg & Center-of-Gravity \\
\hline $\mathrm{D}$ & Capsule Diameter \\
\hline DMSC & Direct Simulation Monte Carlo \\
\hline DOF & Degree-of-Freedom \\
\hline EDL & Entry, Descent, and Landing \\
\hline FPA & Flight-Path Angle \\
\hline LAURA & Langley Aerothermodynamic Upwind Relaxation Algorithm \\
\hline MER & Mars Exploration Rover \\
\hline MPF & Mars Pathfinder \\
\hline POST & Program to Optimize Simulated Trajectories \\
\hline$\alpha$ & Angle-of-Attack \\
\hline$\alpha_{\mathrm{T}}$ & Total Angle-of-Attack \\
\hline $\mathrm{C}_{\mathrm{A}}$ & Axial Force Coefficient \\
\hline$C_{D}$ & Drag Force Coefficient \\
\hline $\mathrm{C}_{\mathrm{m}}$ & Static Pitching Moment Coefficient \\
\hline $\mathrm{C}_{\mathrm{m} \alpha}$ & Static Stability Parameter \\
\hline $\mathrm{C}_{\mathrm{mq}}$ & Dynamic Pitch Damping Coefficient \\
\hline $\mathrm{C}_{\mathrm{N}}$ & Normal Force Coefficient \\
\hline $\mathrm{C}_{\mathrm{n}}$ & Static Yawing Moment Coefficient \\
\hline $\mathrm{C}_{\mathrm{nr}}$ & Dynamic Yaw Damping Coefficient \\
\hline $\mathrm{C}_{\mathrm{Y}}$ & Side Force Coefficient \\
\hline $\mathrm{G} \& \mathrm{C}$ & Guidance and Control \\
\hline$I_{x x}, I_{y y}, I_{z z}$ & Moments of Inertia \\
\hline $\mathbf{I}_{\mathrm{xy}}, \mathbf{I}_{\mathrm{xz}}, \mathbf{I}_{\mathrm{yz}}$ & Cross Products of Inertia \\
\hline $\mathrm{Kn}$ & Knudsen Number \\
\hline $\mathrm{L} / \mathrm{D}$ & Lift-to-Drag Ratio \\
\hline $\mathbf{M}$ & Mach Number \\
\hline$x_{\mathrm{cg}}$ & Axial Center-of-Gravity Location (from capsule nose) \\
\hline
\end{tabular}




\section{REFERENCES}

1. R. B. Roncoli and J. M. Ludwinski, "Mission Design Overview for the Mars Exploration Rover Mission,” AIAA Paper 2002-4823, August 2002.

2. D. A. Spencer, R. C. Blanchard, R. D. Braun, P. H. Kallemeyn, S. W. Thurman, "Mars Pathfinder Entry, Descent, and Landing Reconstruction," Journal of Spacecraft and Rockets, Vol. 36, No. 3, May-June 1999, pp. 357-366.

3. A. Steltzner, P. N. Desai, W. J. Lee, and R. Bruno, "The Mars Exploration Rovers Entry Descent and Landing and the Use of Aerodynamic Decelerators," AIAA Paper 20032125, May 2003.

4. R. D. Braun, R. W. Powell, W. C. Engelund, P. A. Gnoffo, J. K. Weilmunster, R. A. Mitcheltree, "Mars Pathfinder Six-Degree-of-Freedom Entry Analysis," Journal of Spacecraft and Rockets, Vol. 32, No. 6, November-December 1995, pp. 993-1000.

5. G. J., Lebeau, “A Parallel Implementation of Direct Simulation Monte Carlo Method," Computer Methods and Applied Mechanics and Engineering, Vol. 174, 1999, pp. 319337.

6. J. N. Moss, R. G. Wilmoth, and J. M. Price, "DSMC Simulations of Blunt Body Flows for Mars Entries: Mars Pathfinder and Mars Microprobe Capulses," AIAA Paper 97$2508,1997$.

7. F. M. Cheatwood, and P. A. Gnoffo, “A User's Manual for the Langley Aerothermodynamic Upwind Relaxation Algorithm (LAURA),” NASA TM-4674, April 1996.

8. T. M. Flaherty, “Aerodynamics Data Book," TR-3709014, Martin Marietta Corporation, June 1972.

9. F. C. Michel and T. M. Flaherty, "Entry Data Analysis for Viking Landers 1 and 2," TN-3770218, Martin Marietta Corporation, November 1976.

10. P. A. Gnoffo, R. D. Braun, J. K. Weilmunster, R. A. Mitcheltree, W. C. Engelund, and R. W. Powell,, "Prediction and Validation of Mars Pathfinder Hypersonic Aerodynamic Database," Journal of Spacecraft and Rockets, Vol. 36, No. 3, May-June 1999, pp. 367-373.

11. W. Hathaway, “Aerodynamic Results: Mars Explorer Scaled Model Phase II," Eglin Aeroballistic Research Facility, Arrow Tech Associates, January 2002.

12. L. Yates and G. T. Chapman, "Analysis of Data from Ballistic Range Tests of the Mars 2003 Lander Vehicle - Phase II," Aerospace Computing Inc. January 2002. 
13. S. Steinberg, "Experimental Pitch Damping Derivatives for Candidate Viking Entry Configurations at Mach Numbers from 0.6 Through 3.0," TR 3709005, June 1970, Martin Marietta Corporation, Denver Colorado.

14. G. L. Brauer, D. E. Cornick, and R. Stevenson, "Capabilities and Applications of the Program to Optimize Simulated Trajectories (POST)," NASA CR-2770, Feb. 1977.

15. P. N. Desai and F. M. Cheatwood, "Entry Dispersion Analysis for the Stardust Comet Sample Return Capsule," Journal of Spacecraft and Rockets, Vol. 36, No. 3, May-June 1999, pp. 463-469.

16. P. N. Desai and F. M. Cheatwood, "Entry Dispersion Analysis for the Genesis Sample Return Capsule," Journal of Spacecraft and Rockets, Vol. 38, No. 3, May-June 2001, pp. 345-350. 